\title{
Parasexual Crosses by Hyphal Anastomosis and Protoplast Fusion in the Entomopathogen Verticillium lecanii
}

\author{
By C. W. JACKSON*† AND J. B. HEALE \\ Department of Biology, King's College (University of London), Campden Hill Road, \\ London W8 7 AH, UK
}

(Received 27 April 1987; revised 7 August 1987)

\begin{abstract}
Sixty-two 'crosses' were attempted using mixed conidial suspensions and a 'hanging drop' technique involving 21 auxotrophic mutants obtained from seven isolates of Verticillium lecanii. Frequency of heterokaryon formation varied from 0 to $100 \%$, with apparently complete incompatibility being expressed between some isolates, although this was influenced by the particular auxotrophic marker used. Protoplast fusion between compatible isolates usually resulted in prototrophic colonies, but was often unsuccessful when testing apparently incompatible isolates, suggesting that incompatibility was due mainly to nuclear or cytoplasmic factors, rather than to the wall. Evidence for the formation of prototrophic heterozygous diploids was provided by nutritional studies, and DNA content per conidiospore as measured by Feulgen microdensitometry. Conidiospore volume, determined by Coulter counter analysis, was not a reliable indicator of ploidy when investigating parasexual recombination between isolates of differing conidiospore size. Heterozygous diploids generally tended to be unstable, breaking down to yield recombinant haploids; however, four diploids were isolated which remained stable for 3-4 weeks on artificial media.
\end{abstract}

\section{INTRODUCTION}

Genetic studies in the genus Verticillium, with particular emphasis on the plant pathogenic species, have been reviewed recently by Hastie \& Heale (1985) and Heale (1987a), and in the entomopathogenic fungi by Heale $(1982,1987 b$ ). Verticillium lecanii (Zimm.) Viegas, is an entomopathogenic deuteromycete used by Microbial Resources Ltd (formerly Tate \& Lyle) for the control of greenhouse aphids and whitefly (Hall 1981; Jackson et al., 1985). Singh (1972) showed that the nuclear condition (uninucleate conidiospores and hyphal cells) and mitotic division in Cephalosporium coccorum (Petch) $(=V$. lecanii) resembled that of $V$. albo-atrum, and that hyphal fusion and nuclear migration through anastomosing bridges suggested a potential for heterokaryon formation. Nuclear migration following hyphal anastomosis, and recombination between auxotrophic mutants, have provided evidence for heterokaryosis in other entomopathogenic fungi, e.g. Metarhizium anisopliae (Tinline \& Noviello, 1971; Messias \& Azevedo, 1980) and Beauveria bassiana (Yurchenko et al., 1974). Studies on the parasexual cycle have led to the isolation of diploids from many habitually haploid fungi, where standard genetic investigation is precluded by the absence of a sexual stage, e.g. Penicillium chrysogenum (Pontecorvo \& Sermonti, 1954), Fusarium oxysporum (Buxton, 1956), V. albo-atrum (Clarkson \& Heale, 1985; Hastie, 1964) and $M$. anisopliae (Al-Aidroos, 1980).

A necessary prerequisite for the exchange of genetic information via the parasexual cycle is the formation of at least a temporary heterokaryon. Gene flow is therefore limited to those combinations that are heterokaryon compatible. Instances of some degree of heterokaryon

† Present address: Department of Biology, Building 44, The University, Southampton SO9 5NH, UK.

Abbreviation: NTG, $N$-methyl- $N^{\prime}$-nitro- $N$-nitrosoguanidine. 
incompatibility between complementary auxotrophic strains have been reported in Verticillium spp., (Heale, 1966; Typas \& Heale, 1976; Puhalla, 1979). However, interspecific diploids have been formed between $V$. albo-atrum and $V$. dahliae (Hastie, 1973; Typas \& Heale, 1976; Typas, 1983). Hastie (1973) concluded that the recovery of predominantly parental type haploids from such diploids indicated a high degree of chromosomal non-homology between these two species.

Where heterokaryon incompatibility is expressed at the hyphal wall, rather than at the nuclear or cytoplasmic level, it may be overcome by protoplast fusion (Peberdy, 1979). Techniques for protoplast isolation, culture and fusion are now well established (Anné \& Peberdy, 1975; Ferenczy, 1981), and recently a successful protocol for protoplasts of $V$. lecanii has been developed (Jackson, 1984). Typas (1983) performed intra- and interspecific protoplast fusions using strains of $V$. albo-atrum and $V$. dahliae. He concluded that heterokaryon incompatibility operated mainly at the cell wall in these fungi, since by fusing protoplasts heterokaryons were formed between relatively incompatible isolates.

The main aim of this study was to develop basic genetic techniques applicable to a programme for the improvement of $\boldsymbol{V}$. lecanii for more effective commercial control of glasshouse aphids. This paper includes observations on recombination via the parasexual cycle by methods relying on hyphal anastomosis or protoplast fusion, thus indicating the extent of genetic exchange and the possible types of incompatibility expressed between isolates of this entomopathogen.

\section{METHODS}

Fungal isolates and culture conditions. Seven different prototrophic wild-type $V$. lecanii isolates were used (Table 1). Minimal medium (MM) was composed of $3.4 \%(w / v)$ Czapek-Dox liquid mdium (Oxoid) containing $\left(\mathrm{g}^{-1}\right)$ : $\mathrm{NaNO}_{3}(2 \cdot 0), \mathrm{KCl}(0 \cdot 5)$, magnesium glycerophosphate (0.5), $\mathrm{FeSO}_{4} \cdot 7 \mathrm{H}_{2} \mathrm{O}(0 \cdot 01), \mathrm{K}_{2} \mathrm{SO}_{4}(0 \cdot 35)$, sucrose $(30 \cdot 0)$ and 'Japanese' agar (20), made up in distilled water. The complete medium (CM) was MM with the addition of mycological peptone, casein hydrolysate, yeast and malt extract (each at $2 \mathrm{~g} \mathrm{l}^{-1}$ ). Autoclaving was at $121^{\circ} \mathrm{C}$ for 20 min. All cultures were incubated at $22-24^{\circ} \mathrm{C}$ in the dark.

Production of auxotrophic mutants using $N$-methyl- $N^{\prime}$-nitro- $N$-nitrosoguanidine ( $N T G$ ). Conidiospore suspensions $\left(2 \mathrm{ml} \mathrm{at} 10^{7} \mathrm{ml}^{-1}\right)$ were harvested in $0.05 \mathrm{M}$-Tris/maleic acid buffer at $\mathrm{pH} 6$ from 7-d-old spread plates, added to 8 $\mathrm{ml} \mathrm{NTG} \mathrm{solution} \mathrm{(} 2 \mathrm{mg}$ NTG dissolved in $8 \mathrm{ml}$ of buffer) and incubated at $36^{\circ} \mathrm{C}$ for $18-20 \mathrm{~min}$. The conidiospores were then washed twice in $10 \mathrm{ml}$ of buffer by centrifugation at $1000 \mathrm{~g}$ for $10 \mathrm{~min}$, diluted, then spread onto CM plates. Surviving colonies were replica-plated, using a sterile velvet pad, onto $\mathrm{MM}$ and $\mathrm{CM}$ plates. Colonies unable to grow on MM were replica-plated from CM onto a series of supplemented MM plates.

Recombination via hyphal anastomosis. Small droplets of paired conidial suspensions (each at $\left.1 \times 10^{6} \mathrm{ml}^{-1}\right)$ in liquid CM medium were transferred to the lower surface of a Petri dish and moist sterile filter paper was inserted into the upper half. The plates were inverted and incubated for $3-5 \mathrm{~d}$ at $26^{\circ} \mathrm{C}$. Sixty mycelial pellets, each resulting from a single droplet, were divided into batches of 20 , washed twice in $150 \mathrm{ml}$ sterile distilled water and transferred to $\mathrm{MM}$ agar. The proportion of colonies developing from the pellets on $\mathbf{M M}$ plates gave an indication of percentage heterokaryon formation. Controls of separate parent conidial suspensions were treated in the same way to check for reversion.

Protoplast formation and fusion. Hyphal material from $48 \mathrm{~h}$ shake flask cultures incubated at $23^{\circ} \mathrm{C}$ were pretreated with $0.01 \mathrm{M}$-2-mercaptoethanol in McIlvaine's buffer $\left(\mathrm{pH} \mathrm{7.3)}\right.$ at $23{ }^{\circ} \mathrm{C}$ for $1 \mathrm{~h}$, washed, then transferred to enzyme solution $(0.55 \mathrm{M}-\mathrm{KCl}, 3 \%(\mathrm{w} / \mathrm{v})$ cellulase (Sigma type I) and $3 \%(\mathrm{w} / \mathrm{v}) \beta$-glucuronidase (Sigma type $\mathrm{H}-1$ ) in McIlvaine's buffer, $\mathrm{pH} 6.0)$ at $23^{\circ} \mathrm{C}$ for $2 \mathrm{~h}$ to release protoplasts. Protoplast suspension $\left(1 \mathrm{ml} ; 5 \times 10^{6}\right.$ protoplasts $\mathrm{ml}^{-1}$ ) from each of the two auxotrophic strains to be fused was placed in a centrifuge tube and spun $(800 \mathrm{~g})$ for $10 \mathrm{~min}$; the supernatant was removed and $1 \mathrm{ml}$ protoplast fusion solution $\left[30 \%, \mathrm{w} / \mathrm{v}, \mathrm{PEG}\left(M_{\mathrm{r}} 6000\right)\right.$, $0.01 \mathrm{M}-\mathrm{CaCl}_{2}$ in sterile distilled water] was added. After $10 \mathrm{~min}$, the fusing protoplasts were diluted with $0.55 \mathrm{M}-$

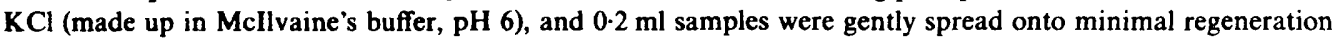
medium (MRM) [1.6\%, w/v, 'Japanese' agar, 0.65 M-sucrose and 3.4\% (w/v) modified Czapek-Dox (without sucrose)] and covered with a thin layer of cool $\left(40^{\circ} \mathrm{C}\right)$ molten MRM. There were three controls. 1. Fused protoplasts were plated on to regeneration medium containing peptone, casein hydrolysate, malt extract and yeast extract (all at $2 \mathrm{~g}^{-1}$ ). 2. After treatment with PEG, protoplasts were lysed in sterile water before plating onto MRM. 3. Protoplasts of individual auxotrophic parent strains were plated onto MRM.

The same initial conidiospore suspension was used to inoculate flasks to provide fungal material for protoplast production, and to set up hanging drops for tests with particular pairs of isolates.

Prototrophic heterozygous diploids and recombinants. For each attempted cross, 10 prototrophic sectors produced on MM or MRM following hyphal anastomosis or protoplast fusion respectively, were selected and transferred separately onto fresh MM. Conidiospores were harvested from the resulting colonies and three replicate MM 
Table 1. Isolates of $V$. lecanii, their origin, and stable auxotrophic mutants isolated following treatment with NTG

C3 and C42 were supplied by Dr R. A. Hall, Glasshouse Crops Research Institute, UK. All other isolates were supplied by Dr W. Gams, Centraal bureau voor Schimmelcultures, Baarn, Holland. Auxotrophic mutants are designated according to Demerec et al. (1966). Diauxotrophic mutants were isolated following two cycles of mutagenesis with NTG.

Isolate Origin

\begin{tabular}{|c|c|}
\hline $\mathrm{C} 42$ & Myzus persicae (aphid) \\
\hline $\mathrm{C} 3$ & $\begin{array}{l}\text { Macrosiphoniella sanborni } \\
\text { (aphid) }\end{array}$ \\
\hline $455.70 \mathrm{~B}$ & Unknown \\
\hline 123.42 & Citobotium schiedei (fern) \\
\hline 413.70B & $\begin{array}{l}\text { Saccharomyces cerevisiae } \\
\text { (yeast) }\end{array}$ \\
\hline $\begin{array}{l}318.70 \mathrm{C} \\
132.56\end{array}$ & $\begin{array}{l}\text { Saissetia nigra (insect) } \\
\text { Soil }\end{array}$ \\
\hline
\end{tabular}

Auxotrophic mutants (code numbers)

met-1 arg-1 (A1), met-2lys-1 (A2), met-2 arg-2 (A3)

lys-2 leu-1 (B1), lys-2 ade-1 (B2), arg-3 gly-1 (B3), arg-3 trp-1 (B4), arg-3 trp-2 (B5), arg-3 ade-2 (B6), arg-3 met-3 (B7), arg-3 met-4 (B8), met-5 lys-3 (B9)

USSR

Netherlands

FRG pan-1 ade-3 (C1), pan-1 arg-4 (C2), thi-I (C3), met-6 (D1)

Czechoslovakia Africa (Zaire)

arg-6 pan-2 (F1), arg-6 pan-3 (F2), arg-6 ade-5 (F3) met-7 ade-6 (G1)

plates spread with $10^{7}, 10^{4}$ and $10^{2}$ conidiospores per plate. The number of colonies developing compared with the number of conidiospores plated resulted in estimates for percentage prototrophy.

Feulgen DNA and Coulter counter analysis. Feulgen DNA microdensitometry and Coulter counter analysis (Jackson \& Heale, 1985) were done on all wild-type isolates and on a selection of prototrophic recombinants following hyphal anastomosis or protoplast fusion, for estimates of nuclear DNA content and spore volume respectively. For the Feulgen technique, an internal control (isolate B) was incorporated in every slide to reduce experimental error due to any differences in hydrolysis conditions.

\section{RESULTS}

After treatment with NTG a number of stable monoauxotrophic mutants were obtained; mutagenic treatment was repeated to produce diauxotrophs (Table 1). Crosses were attempted by hyphal anastomosis or protoplast fusion between selected pairs of auxotrophs.

The results from 62 attempted crosses involving hyphal anastomosis between 21 auxotrophic mutants from seven different parent isolates (Table 2) indicated a considerable variation in the percentage heterokaryon formation. This was reflected in the number of resulting pellets that produced prototrophic heterokaryotic growth when transferred to MM (Table 2). The heterokaryons grew more slowly than parental cultures, but produced fast-growing, V-shaped heterozygous diploid sectors. The values ranged from $100 \%$ heterokaryon formation for six independent crosses between isolates $\mathbf{A}$ and $\mathbf{B}$, to apparently totally incompatible combinations as indicated in three independent crosses between isolates $\mathrm{D}$ and $\mathrm{F}$. All five intra-isolate crosses between complementary mutants of isolate $B$ resulted in $100 \%$ heterokaryon formation and the subsequent production of heterozygous diploids (Table 2); values of less than $100 \%$ would have reflected the influence of factors other than incompatibility. Attempted selection for prototrophs (heterozygous diploids or recombinant diploids or haploids) from heterokaryons by sampling conidia on $M M$ at high density involving $F \times G$ failed, as did other combinations of these isolates with $\mathrm{B}, \mathrm{C}$ and $\mathrm{D}$. The only isolate to produce heterozygous diploids when crossed with $F$ or $G$ was $A$ (Table 2). One of four crosses involving $A \times F$ resulted in heterozygous diploids associated with low (8\%) heterokaryon formation; only one of three attempted crosses using $A \times G(A 1 \times G 1$ and $A 2 \times G 1)$ resulted in diploids combined with a low $(20 \%)$ heterokaryon formation. Of the remaining five isolates, $E$ resulted in low percentage heterokaryon formation for the pairings tested, although heterozygous diploids were obtained between this isolate and isolates A, B, C and D, indicating that percentage heterokaryon values were not correlated with the incidence of karyogamy occurring subsequently.

$A$ and $B$ were apparently highly compatible with each other, as were isolates $C$ and $D$. Isolate $\mathrm{C}$ was also highly compatible with $\mathrm{B}$. Percentage heterokaryon formation values and the ability 
Table 2. Percentage heterokaryon formation and heterozygous diploid production following hyphal anastomosis between auxotrophic mutants of $V$. lecanii

See Table 1 for details of auxotrophic mutants. Percentage heterokaryon formation $=$ no. of hyphal pellets growing on $\mathrm{MM} /$ total no. (60) of pellets plated $\times 100$.

\begin{tabular}{|c|c|c|c|c|c|c|c|c|c|c|c|c|c|c|}
\hline $\begin{array}{c}\text { Parental } \\
\text { isolates }\end{array}$ & B1 B2 & B3 & B5 & B6 & B8 & B9 & $\mathrm{Cl}$ & $\mathrm{C} 2$ & DI & El & $\mathrm{Fl}$ & F2 & F3 & G1 \\
\hline Al & $100^{*} 100^{*}$ & & & & & & $\begin{array}{l}10^{*} \\
22^{*}\end{array}$ & & & & & & & $\begin{array}{c}20^{*} \\
0\end{array}$ \\
\hline A2 & & $100^{*}$ & $100^{*}$ & $100^{*}$ & & & $\begin{array}{l}8^{*} \\
0\end{array}$ & $\begin{array}{l}0^{*} \\
0\end{array}$ & & $\begin{array}{c}63^{*} \\
0\end{array}$ & $\begin{array}{c}20 \\
0\end{array}$ & 0 & $8^{*}$ & 0 \\
\hline A3 & $100^{*}$ & & & & & & $40^{*}$ & $24^{*}$ & & & & & & \\
\hline Bl & & & $100^{*}$ & $100^{*}$ & & & $60^{*}$ & 0 & $2^{*}$ & $1 \cdot 6^{*}$ & 4.5 & & 0 & 0 \\
\hline $\begin{array}{l}\text { B2 } \\
\text { B3 }\end{array}$ & & & $100^{*}$ & & $100^{*}$ & & $32 *$ & 0 & $2^{*}$ & $3 \cdot 3$ & $2 \cdot 4$ & & & \\
\hline B4 & & & & & & & $100^{*}$ & & 0 & & & & & 0 \\
\hline B5 & & & & & & & $100^{*}$ & & 0 & & & & & \\
\hline B6 & & & & & & $100^{*}$ & & & 0 & & & & & \\
\hline B7 & & & & & & & $22^{*}$ & & & & & & & \\
\hline B8 & & & & & & & $8^{*}$ & & & & & & & \\
\hline $\mathrm{Cl}$ & & & & & & & & & $100^{*}$ & $\begin{array}{l}1 \cdot 6^{*} \\
4\end{array}$ & & & & \\
\hline $\mathrm{C} 2$ & & & & & & & & & $60^{*}$ & 0 & & & & $\begin{array}{l}0 \\
0\end{array}$ \\
\hline C3 & & & & & & & & & & 0 & & & & \\
\hline D1 & & & & & & & & & & $\begin{array}{r}21 \cdot 6^{*} \\
1.5^{*}\end{array}$ & 0 & 0 & 0 & \\
\hline $\mathrm{Fl}$ & & & & & & & & & & & & & & $5 \cdot 5$ \\
\hline
\end{tabular}

- Spores harvested from 10 prototrophic sectors from selected heterokaryons were transferred to MM, which resulted in colony formation (prototrophic heterozygous diploids or recombinants). Not all sectors necessarily resulted in single-spored prototrophic growth.

to produce heterozygous diploids sometimes varied between repeat tests, however, and also depended on the auxotrophic markers used (Table 2).

Percentage protoplast fusion, expressed as the number of colonies regenerating on $\mathrm{MM}$ compared to $\mathrm{CM}$, was extremely varied and depended partly on how the fusion products were handled before plating out. The greater the disturbance, the smaller the clumps of fused protoplasts, which resulted in a lower percentage regeneration. Thus, indications of compatibility as expressed by protoplast fusion are presented qualitatively as the ability (or lack of it) to produce prototrophic colonies (heterozygous diploids and/or prototrophic recombinants) after single-sporing from regenerating growths from a 'protoplast cross' between auxotrophic strains (Table 3).

In order to investigate the influence of the hyphal wall on the ability to yield prototrophic colonies, pairs of auxotrophic mutants were combined both by hyphal anastomosis and by protoplast fusion: 38 crosses were attempted between 16 auxotrophic mutants derived from seven different parent isolates (Table 3). In the majority of crosses (25), the ability to produce prototrophic colonies (heterozygous diploids or haploid recombinants) was the same by either method. In six crosses - B1 $\times \mathrm{G} 1, \mathrm{~B} 6 \times \mathrm{D} 1, \mathrm{C} 3 \times \mathrm{E} 1, \mathrm{C} 2 \times \mathrm{A} 2, \mathrm{C} 2 \times \mathrm{B} 2$ and $\mathrm{C} 2 \times \mathrm{E} 1-$ protoplast fusion resulted in the successful production of heterozygous diploids, whereas using the same markers hyphal anastomosis failed to do so. Both protoplast fusion and hyphal anastomosis were influenced by the particular auxotrophic markers used: thus A2 $\times$ F2 and D1 $\times \mathrm{B} 5$ failed to produce heterozygous diploids, whereas $\mathrm{A} 2 \times \mathrm{F} 3$ and $\mathrm{D} 1 \times \mathrm{B} 2$ did so.

Six crosses $(\mathrm{B} 1 \times \mathrm{Cl}, \mathrm{B} 1 \times \mathrm{E} 1, \mathrm{~B} 4 \times \mathrm{Cl}, \mathrm{Cl} \times \mathrm{D} 1, \mathrm{Cl} \times \mathrm{E} 1$ and $\mathrm{D} 1 \times \mathrm{E} 1)$, failed to produce diploids after protoplast fusion, but did so following hyphal anastomosis (Table 3 ); however, percentage heterokaryon formation was less than $60 \%$ in all but two crosses.

Percentage diploidy, estimated by scoring the number of conidiospores (from 10 selected heterokaryons) able to produce colonies on MM (Table 4), ranged from 0 to $19 \%$. Generally, 
Table 3. Heterozygous diploid formation following protoplast fusion or hyphal anastomosis between auxotrophic mutants of $V$. lecanii

See Table 1 for details of auxotrophic combinations. Growth of prototrophic colonies from single spores is taken as evidence for the formation of heterozygous diploids. $(\mathrm{H})=$ cross done by hyphal anastomosis; $(\mathrm{P})=$ cross done by protoplast fusion. $\mathbf{X}=$ growth on $\mathbf{M M}$ from single conidiospores harvested from prototrophic growth; $0=$ no protrophic growth on $\mathbf{M M}$.

\begin{tabular}{|c|c|c|c|c|c|c|c|c|c|c|c|}
\hline $\begin{array}{l}\text { Parental } \\
\text { isolates }\end{array}$ & B5 & B6 & B8 & $\mathrm{Cl}$ & $\mathrm{C} 2$ & D1 & E1 & F1 & F2 & F3 & G1 \\
\hline $\begin{array}{r}\mathrm{A} 2(\mathrm{H}) \\
(\mathrm{P})\end{array}$ & $\begin{array}{l}\mathbf{X} \\
\mathbf{X}\end{array}$ & $\begin{array}{l}\mathbf{X} \\
\mathbf{X}\end{array}$ & & $\begin{array}{l}\text { X0 } \\
\text { X0 }\end{array}$ & $\begin{array}{l}00 \\
X 0\end{array}$ & & $\begin{array}{l}\text { X0 } \\
\text { X0 }\end{array}$ & & $\begin{array}{l}0 \\
0\end{array}$ & $\begin{array}{l}\mathbf{X} \\
\mathbf{X}\end{array}$ & $\begin{array}{l}0 \\
0\end{array}$ \\
\hline $\mathrm{B} 1(\mathrm{H})$ & $\mathbf{X}$ & $\mathbf{X}$ & & $\mathrm{X}$ & 0 & $\mathrm{X}$ & $\mathrm{X}$ & & & & 0 \\
\hline (P) & $\mathrm{X}$ & $\mathbf{x}$ & & 0 & 0 & $\mathbf{X}$ & 0 & & & & $\mathrm{x}$ \\
\hline B2 $(\mathrm{H})$ & $\mathbf{X}$ & & $\mathbf{X}$ & & 0 & $\mathrm{X}$ & 0 & & & & \\
\hline (P) & $\mathrm{X}$ & & $\mathbf{X}$ & & $\mathbf{X}$ & $\mathbf{X}$ & 0 & & & & \\
\hline B4 (H) & & & & $\begin{array}{l}\mathrm{X} \\
0\end{array}$ & & & & & & & \\
\hline $\begin{array}{r}\text { (P) } \\
\text { B5 (H) }\end{array}$ & & & & $\begin{array}{l}0 \\
X\end{array}$ & & 0 & & & & & \\
\hline (P) & & & & $\hat{X}$ & & 0 & & & & & \\
\hline B6 (H) & & & & & & 0 & & & & & \\
\hline (P) & & & & & & $\mathbf{X}$ & & & & & \\
\hline $\mathrm{Cl}(\mathrm{H})$ & & & & & & $\mathbf{X}$ & X0 & & & & \\
\hline (P) & & & & & & 0 & 00 & & & & \\
\hline $\mathrm{C} 2(\mathrm{H})$ & & & & & & $\mathbf{X}$ & 0 & & & & 0 \\
\hline (P) & & & & & & $\mathbf{X}$ & $\mathbf{X}$ & & & & 0 \\
\hline $\mathrm{C} 3(\mathrm{H})$ & & & & & & & 0 & & & & \\
\hline (P) & & & & & & & $\mathbf{x}$ & & & & \\
\hline D1 (H) & & & & & & & $\mathbf{X X}$ & 0 & 0 & & \\
\hline (P) & & & & & & & 00 & 0 & 0 & & \\
\hline
\end{tabular}

Table 4. Comparison of percentage diploidy values obtained following either protoplast fusion or hyphal anastomosis between complementary auxotrophic mutants of $V$. lecanii

For each cross, 10 heterokaryons were selected; conidiospores were washed off and plated at $10^{7}, 10^{4}$ and $10^{2}$ conidiopores per plate (three replicates) on MM. Percentage diploidy was scored as the proportion of conidiospores developing into prototrophic colonies.

Range of percentage diploidy

Cross*

A2 $\times$ B5

A2 $\times$ B6

$\mathrm{A} 2 \times \mathrm{Cl}$

$\mathrm{A} 2 \times \mathrm{C} 2$

$\mathrm{A} 2 \times \mathrm{E} 1$

A2 $\times$ F3

$\mathrm{B} 1 \times \mathrm{Cl}$

B4 $\times \mathrm{Cl}$

B5 $\times \mathrm{Cl}$

$\mathrm{B} 2 \times \mathrm{C} 2$

B1 $\times$ D1

$B 2 \times D 1$

B1 $\times$ E1

B1 $\times$ G1

$\mathrm{Cl} \times \mathrm{D} 1$

$\mathrm{C} 2 \times \mathrm{D} 1$

$\mathrm{C} 1 \times \mathrm{E} 1$

$\mathrm{C} 2 \times \mathrm{E} 1$

$\mathrm{C} 3 \times \mathrm{E} 1$

D1 $\times$ El

D1 $\times$ E1

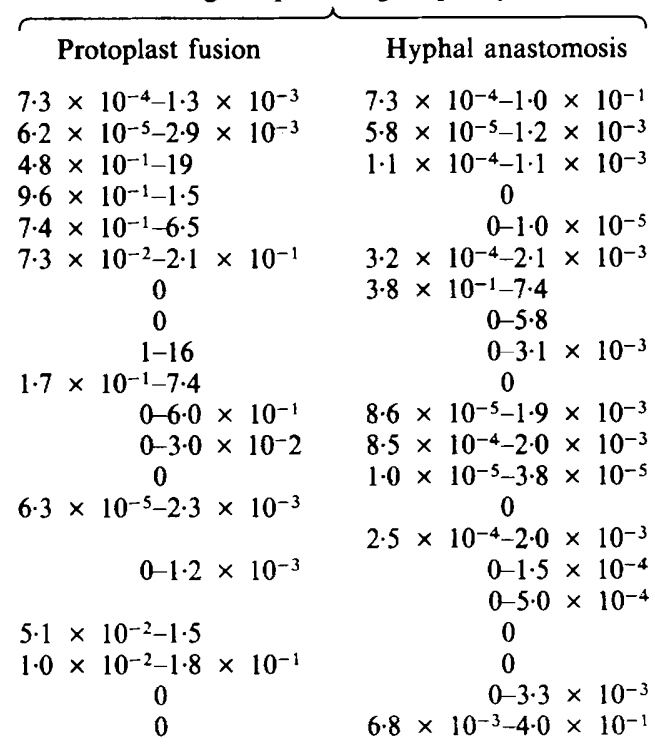

* See Table 1. 
Table 5. Conidiospore volumes (Coulter counter) and DNA content (Feulgen DNA microdensitometry) of spores from prototrophic colonies produced from paired auxotrophic strains via hyphal anastomosis or protoplast fusion

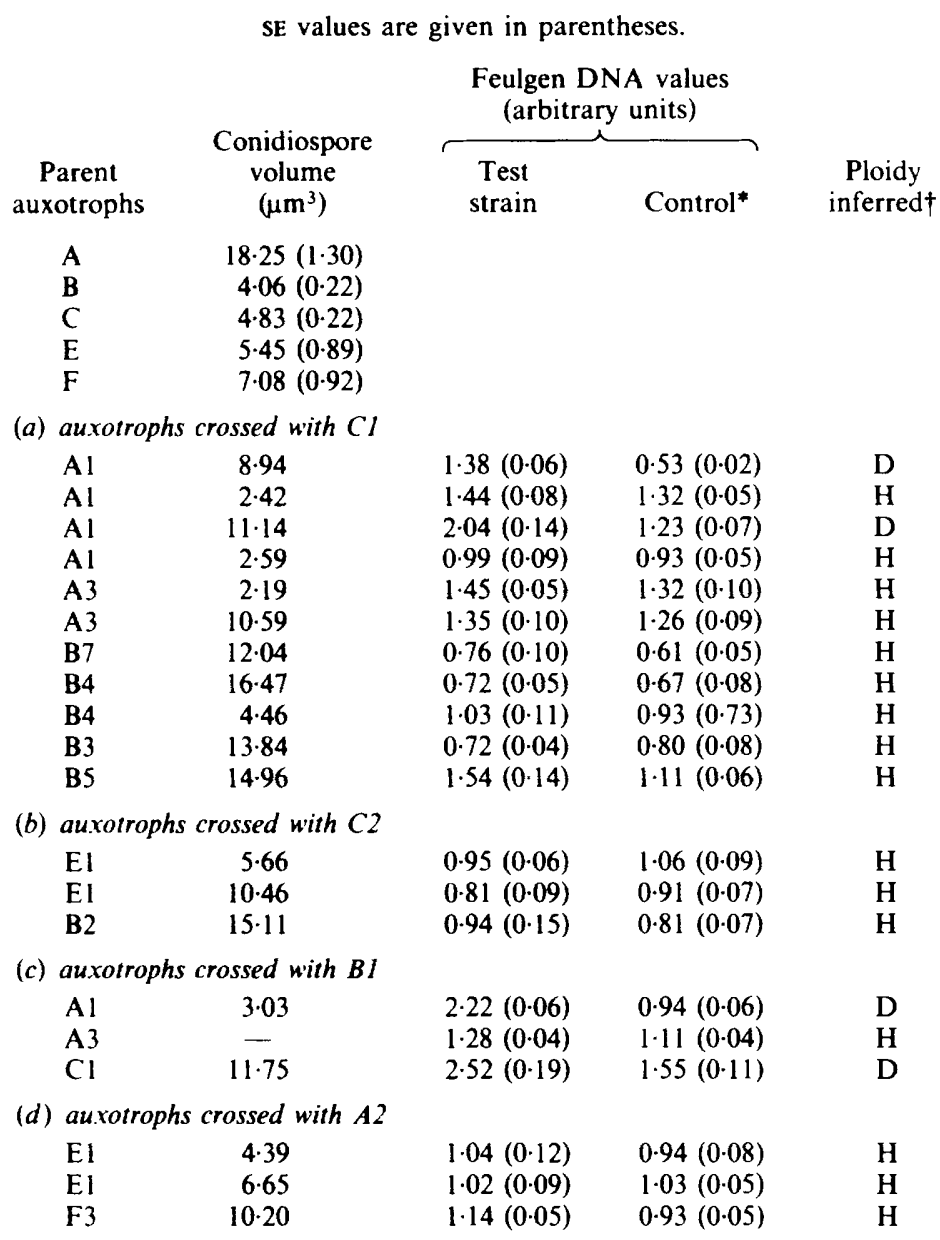

* The control was haploid $V$. lecanii isolate B, an internal control on the same slide to reduce variability.

$+\mathrm{D}=$ diploid, $\mathrm{H}=$ haploid.

yields of diploids obtained following protoplast fusion were slightly higher than yields obtained using mixed spore suspensions in hanging drops, but considerable variability was found depending upon the manipulative techniques used in preparing the protoplasts.

Heterozygous diploids, which remained stable for 4-5 weeks on artificial media, were confirmed by Feulgen DNA microdensitometry for the following crosses: $\mathrm{Cl} \times \mathrm{Al} ; \mathrm{Cl} \times \mathrm{Bl}$ and $\mathrm{Al} \times \mathrm{B} 1$ (Table 5). The remaining prototrophic colonies tested gave microdensitometry values near the internal haploid control, which indicated they were prototrophic aneuploid or haploid recombinants. Results for the control values varied greatly between slides, thus emphasizing the requirement for the internal control on the same slide. Variability within a slide was small as indicated by the SE values (Table 5).

Prototrophic sectors from different heterokaryon areas within the same culture differed in their ability to produce stable diploids, i.e. $\mathrm{Cl} \times \mathrm{Al}$ (Table 5). The three auxotrophs that produced stable diploids when 'paired' did so for every combination $(\mathrm{Cl} \times \mathrm{Al}, \mathrm{Cl} \times \mathrm{B} 1$ and $\mathrm{Al}$ $\times B 1$ ) between each of the three, but not with any of the other auxotrophs tested here. The 


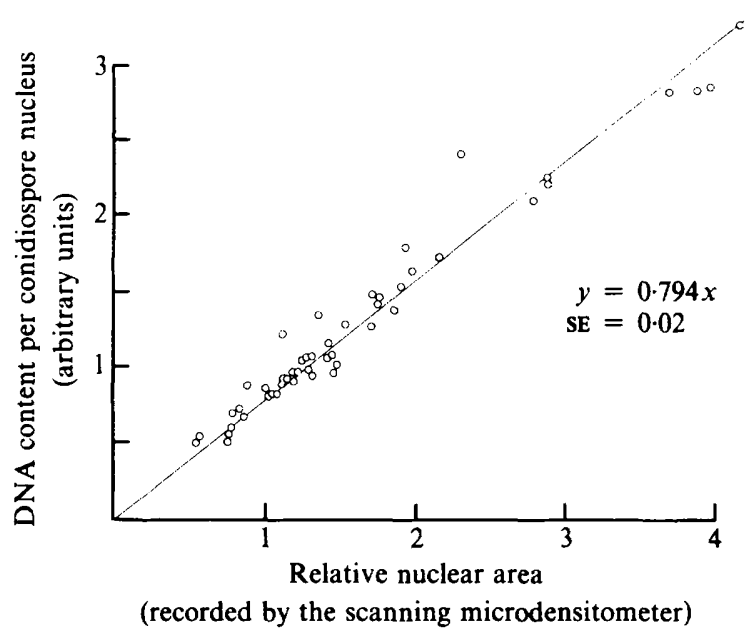

Fig. 1. Relationship between DNA content per nucleus and nuclear area of $V$. lecanii conidiospores, from a mixture of conidiospores isolated from a diploid undergoing haploidization.

ability to form a stable prototrophic inter-isolate diploid again depended partly on the particular marker used, e.g. A3 did not form stable diploids in several crosses but A1 did (Table 5).

The relationship between DNA content per conidiospore nucleus and conidiospore volume was extremely variable. Only in one cross tested $(\mathrm{Cl} \times \mathrm{Al})$ were the diploid conidiospores substantially larger $\left(8.94-11 \cdot 14 \mu \mathrm{m}^{3}\right)$ than haploid recombinants $\left(2.42-2.59 \mu \mathrm{m}^{3}\right)$ (Table 5). Conidiospore size was not usually a reliable indicator of ploidy for crosses between isolates of markedly different sized conidiospores. However, the nuclear area (also recorded by the microdensitometer) of Feulgen-stained conidiospores was directly related to integrated density values (Fig. 1). Although it appears that DNA content per conidiospore ranged from approximately $0 \cdot 5-3$, the units used were 'arbitrary'.

Additional evidence for the formation of heterozygous diploids was provided by the genetic analysis of six selected prototrophs (four from 'selfing' B and two from B $\times$ A). For each cross, three single conidiospore isolations from prototrophic colonies were subcultured onto $\mathrm{CM}$ plates. After approximately 2 weeks growth, conidiospores were harvested from the sectoring daughter colonies in sterile distilled water, diluted as necessary and spread on fresh CM plates to give 20-30 colonies per plate. The genotypes of the conidiospores from the colonies which subsequently developed were determined by replica-plating onto appropriately supplemented $\mathrm{MM}$ and recombinants with different requirements to the parent auxotrophs were recovered in each case (Table 6).

As a result of all attempted crosses, complementation analysis revealed non-allelic mutations for adenine $(\mathrm{E} 1 \times \mathrm{B} 2$ and $\mathrm{E} 1 \times \mathrm{C} 1)$, arginine $(\mathrm{C} 2 \times \mathrm{A} 3$ and $\mathrm{C} 2 \times \mathrm{E} 1)$ and methionine $(\mathrm{A} 1 \times$ Gl) in the strains used.

\section{DISCUSSION}

The successful formation of a heterokaryon is an essential prerequisite for any parasexual recombination between different fungal strains. Heterokaryon incompatibility as reported between strains of $V$. dahliae, $V$. albo-atrum and $V$. tricorpus (Hastie, 1973, 1978; Typas \& Heale, 1976) is probably due to evolutionary diversification, which has resulted in relative genetic nonhomology at the species level. More recently however, Typas (1983) has found strong evidence of extensive mitotic crossing over in certain hybrids between $V$. albo-atrum and $V$. dahliae. This, together with the high degree of complementation of gene activity, led the author to conclude that there is a substantial degree of homology between the haploid genomes of $V$. albo-atrum and 
Table 6. Genetic analysis of recombinants arising from spore analysis of prototrophic diploid cultures originating from six selected heterokaryons of $V$. lecanii

Prototrophic diploids were selected from six different heterokaryon pairs and the genotype of segregants formed on $\mathrm{CM}$ was determined by replica-plating spores on to appropriately supplemented MM.

\begin{tabular}{|c|c|c|c|c|}
\hline $\begin{array}{c}\text { Heterokaryon } \\
\text { pair }\end{array}$ & $\begin{array}{l}\text { Genotypes } \\
\text { recovered }\end{array}$ & $\begin{array}{l}\text { No. } \\
\text { (thre }\end{array}$ & & \\
\hline $\mathrm{B} 1 \times \mathrm{B} 6$ & $\begin{array}{c}\text { arg }+++ \\
++y s+ \\
++l y s \text { leu } \\
++++\end{array}$ & $\begin{array}{r}17 \\
0 \\
10 \\
22\end{array}$ & $\begin{array}{r}30 \\
5 \\
0 \\
8\end{array}$ & $\begin{array}{r}33 \\
5 \\
0 \\
0\end{array}$ \\
\hline $\mathrm{B} 6 \times \mathrm{B} 9$ & $\begin{array}{l}\text { arg ade }++ \\
++ \text { met lys } \\
+ \text { ade met lys } \\
+ \text { ade }+ \text { lys } \\
++++\end{array}$ & $\begin{array}{r}17 \\
25 \\
0 \\
0 \\
1\end{array}$ & $\begin{array}{r}12 \\
0 \\
1 \\
0 \\
0\end{array}$ & $\begin{array}{r}10 \\
15 \\
13 \\
4 \\
0\end{array}$ \\
\hline $\mathrm{B} 2 \times \mathrm{B} 5$ & $\begin{array}{c}\text { arg trp }++ \\
++ \text { lys ade } \\
++++\end{array}$ & $\begin{array}{r}10 \\
13 \\
0\end{array}$ & $\begin{array}{r}4 \\
15 \\
4\end{array}$ & $\begin{array}{r}10 \\
8 \\
0\end{array}$ \\
\hline $\mathrm{B} 1 \times \mathrm{B} 5$ & $\begin{array}{c}\arg \operatorname{trp}++ \\
++l_{+}+ \\
\arg +++ \\
++++\end{array}$ & $\begin{array}{r}16 \\
19 \\
0 \\
11\end{array}$ & $\begin{array}{r}21 \\
23 \\
0 \\
0\end{array}$ & $\begin{array}{r}0 \\
25 \\
6 \\
1\end{array}$ \\
\hline $\mathrm{A} 2 \times \mathrm{B} 5$ & $\begin{array}{c}\text { arg trp }++ \\
++ \text { met lys } \\
+++ \text { lys } \\
++ \text { met }+ \\
+ \text { trp }+ \text { lys } \\
\text { arg trp }+ \text { lys } \\
++++\end{array}$ & $\begin{array}{r}2 \\
0 \\
21 \\
0 \\
0 \\
0 \\
15\end{array}$ & $\begin{array}{r}6 \\
16 \\
0 \\
0 \\
2 \\
0 \\
15\end{array}$ & $\begin{array}{r}4 \\
14 \\
0 \\
2 \\
0 \\
2 \\
20\end{array}$ \\
\hline$A 1 \times B 2$ & $\begin{array}{c}\text { lys ade }++ \\
++ \text { met arg } \\
++ \text { met }+ \\
\text { lys }+ \text { met }+ \\
++++\end{array}$ & $\begin{array}{r}7 \\
12 \\
0 \\
1 \\
2\end{array}$ & $\begin{array}{r}11 \\
17 \\
2 \\
0 \\
13\end{array}$ & $\begin{array}{r}6 \\
11 \\
0 \\
0 \\
3\end{array}$ \\
\hline
\end{tabular}

$V$. dahliae. The occurrence of heterokaryon incompatibility between some isolates of $V$. lecanii, as reported here, should not be particularly surprising as taxonomically it is an extremely diverse species (Gams, 1971). Furthermore, the isolates chosen came from widely differing hosts and geographical origins.

The role of heterokaryon incompatibility systems is thought to be at least twofold: firstly, the limitation of genetic exchange, thus maintaining a stable identity, and secondly, to prevent the spread of harmful cell inclusions, such as viruses or mutant suppressive mitochondria (Cater, 1971: Day, 1974). Genetic exchange between compatible strains may nevertheless result in recombinant progeny with a selective advantage over parental strains. Occasional errors or mutational change in alleles controlling incompatibility may allow rare gene transfer between heterogeneous populations of wild fungi.

Puhalla (1979) classified 19 isolates of the plant pathogenic $V$. dahliae species from different geographical origins and hosts into four distinct heterokaryon compatibility (h-c) groups, within which all isolates readily formed heterokaryons with other members of that group, but not with isolates from other h-c groups. Puhalla \& Hummel (1981) later extended the number of $V$. dahliae isolates assessed in this way to 94 , subdivided into at least $16 \mathrm{~h}$-c groups. Aspergillus nidulans has a number of h-c groups (Croft \& Jinks, 1977) under nuclear control; allelic differences between strains at any one of the het gene loci resulted in incompatibility. Evidence for a mitochondrial incompatibility mechanism, also operating in Aspergillus spp., was provided by Croft \& Dales (1983). 
The results of the present limited study could be interpreted as indicating the existence of at least $5 \mathrm{~h}$-c groups in $V$. lecanii, although there was a low incidence ( $20 \%$ or less) of heterokaryon formation between the groups. Three isolates, E, F and G, resulted in extremely low or zero percentage heterokaryon formation, often failing to produce heterozygous diploids or recombinants. A and B made up the fourth h-c group being highly compatible with each other, and $\mathrm{D}$ the fifth. C, however, was compatible with two h-c groups, D and A/B. The fact that in $V$. lecanii the same cross, when repeated, sometimes resulted in an altered expression of compatibility as defined by percentage heterokaryon formation or the ability to produce prototrophic recombinants, could be explained by the operation of cytoplasmic factors as suggested by Hastie (1978) for $V$. albo-atrum. Typas (1983) observed similar variation in heterokaryon formation in paired isolates of $V$. albo-atrum and $V$. dahliae; he used the terms heterokaryon former, partial former and non-former to explain this phenomenon. Our work agrees with the findings of Typas (1983), suggesting that the control of compatibility in Verticillium is more complicated than originally believed. Further, when the percentage heterokaryon formation was low, the inability to produce a compatible result in some tests may have been due to the experimental sample being too small : thus $\mathrm{C} 2 \times \mathrm{A} 2$ resulted in $0 \%$ and $8 \%$ heterokaryon formation in replicate experiments.

The use of auxotrophs in investigations of heterokaryosis has been criticized (Caten \& Jinks, 1966) because of the strong selective advantage conferred on the heterokaryon by the complementary action of the genetic markers. 'Forcing' might therefore overcome incompatibility barriers that exist in the wild. However Puhalla (1979) and Puhalla \& Hummel (1981) tested heterokaryon compatibility between isolates of $V$. dahliae either using complementary microsclerotial pigment mutants or similar pairings on minimal medium between diauxotrophic strains and the results indicated that the use of a selective or non-selective marker did not alter the heterokaryon compatibility groupings. The pattern of heterokaryon formation observed for $V$. lecanii here indicates that compatibility is not under simple monogenic control. This is in agreement with observations by Clarkson \& Heale (1985) for hop strains of the plant pathogen $V$. albo-atrum. The lack of clearly defined compatibility groups, and the strong influence of nutritional requirements, suggests that heterokaryon formation and heterozygous diploid production may both be under polygenic control.

In some circumstances where heterokaryon incompatibility is expressed at the hyphal wall, the use of protoplast fusion makes it possible to remove this component, thus achieving heterokaryosis where conventional parasexual methods are unknown or difficult to manipulate. Protoplast fusion has been reported for both intraspecific (Typas, 1983; Dales \& Croft, 1979) and interspecific (Anné \& Peberdy, 1975) recombination. However, the type of heterokaryon incompatibility mechanism operating has a profound effect on the interspecific hybrids obtained, and the ease with which they can be obtained via protoplast fusion (Croft $\&$ Dales, 1983).

Results of parallel experiments comparing protoplast fusion with conventional parasexual techniques in $V$. lecanii indicated that only in a limited number of crosses was protoplast fusion able to overcome apparent total heterokaryon incompatibility (as expressed during hyphal anastomosis by $0 \%$ heterokaryon formation). As mentioned earlier, caution must be expressed over these results, for at very low percentage heterokaryon formation this apparent difference could be due to a lack of repeatability. Several other crosses that were apparently incompatible by conventional parasexual techniques, however, did not result in genetic recombination following protoplast fusion. This would suggest that although incompatibility can act at the hyphal wall, other mechanisms acting at the cytoplasmic and/or nuclear level, such as those described by Typas (1983) or Wilson et al. (1961), are probably more important in $V$. lecanii. In addition, the formation of heterokaryons without the production of heterozygous diploids or prototrophic recombinants as seen in $B \times F$ and $G \times F$ could result from nuclear incompatibility preventing karyogamy (Hastie, 1973, 1978). Typas (1983) reported a 1000-fold increase in heterozygous diploid formation following protoplast fusion or micro-injection for $V$. albo-atrum and $V$. dahliae. The data presented here do not support this for $V$. lecanii, for although percentage diploidy values tended to be higher following protoplast fusion, variability of results masked any clear-cut differences. 
The majority of heterozygous diploids synthesized in this study between auxotrophic strains of $V$. lecanii were unstable, as reported for other Verticillium spp. (Hastie, 1964; Puhalla \& Mayfield, 1974; Typas \& Heale, 1976; Clarkson, 1982). Isolates A, B and C were the only isolates which, when crossed with each other, formed diploids which were stable for 4-5 weeks on artificial medium. Similar stable heterozygous diploids have been produced using auxotrophs of $V$. albo-atrum (McGeary \& Hastie, 1981 ; Clarkson \& Heale, 1985). In both studies, the ability to produce such stable diploids was influenced by the auxotrophic markers used. McGeary \& Hastie (1981) hypothesized that unstable diploids were a result of the simultaneous induction of an auxotrophic and chromosomal mutation in one nucleus by mutagen treatment, instability being due to heterozygosity at the point of chromosomal aberration.

The results of the present studies with $V$. lecanii indicate that although heterokaryon incompatibility is expressed between certain isolates, it is usually possible to produce rare heterozygous diploids and recombinants between selected isolates. Thus, parasexual techniques are of potential value for studies aimed at improving the epizootic efficacy of this and other entomopathogenic fungi against selected insect hosts.

We thank the SERC and Microbial Resources Ltd (formerly Tate \& Lyle) for financial assistance via a CASE award to $C$. W. Jackson during the period when the research was carried out.

\section{REFERENCES}

AL-AIDRoOs, K. (1980). Demonstration of a parasexual cycle in the entomopathogenic fungus Metarhizium anisopliae. Canadian Journal of Genetics and Cytology 22, 309-314.

Anné, J. \& Peberdy, J. F. (1975). Conditions for induced fusion of fungal protoplasts in polyethylene solutions. Archives of Microbiology 105, 201-205.

BUXTON, E. W. (1956). Heterokaryosis and parasexual recombination in pathogenic strains of Fusarium oxy'sporum. Journal of General Microbiology 15, 133139.

CATEN, C. E. (1971). Heterokaryon incompatibility in imperfect species of Aspergillus. Heredity 26, 299312.

CAten, C. E. \& Jinks, J. L. (1966). Heterokaryosis: its significance in wild homothallic ascomycetes and fungi imperfecti. Transactions of the British Mycological Society 49, 81-93

Clarkson, J. M. (1982). Genetical studies on strains of Verticillum albo-atrum ( $R$ and $B$ ) causing vascular wilt disease in hop (Humulus lupulus L). PhD thesis, Queen Elizabeth College, University of London.

Clarkson, J. M. \& Heale, J. B. (1985). Heterokaryon compatibility and genetic recombination within a host plant between hop wilt isolates of Verticillium albo-atrum. Plant Pathologyu 34, 129-138.

Croft, J. H. \& Dales, R. B. G. (1983). Interspecific somatic hybridisation in Aspergillus. In Protoplasts 1983. lecture proceedings of the 6th International Protoplast Symposium, Basel, August 12-16, 1983, pp. I 79-185. Edited by I. Potrykus, C. T. Harms, A. Hinnen, R. Hutter, P. J. King \& R. D. Shillito. Basel: Birkhauser Verlag.

Croft, J. H. \& Jinks, J. L. (1977). Aspects of the population genetics of Aspergillus nidulans. In Genetics and Physiology of Aspergillus, pp. 339-360. Edited by J. E. Smith \& J. A. Pateman. London: Academic Press.

Dales, R. B. G. \& Croft, J. H. (1979). Protoplast fusion and the genetical analysis of vegetative incompatibility in Asperqillus nidulans. In Advances in Protoplast Research. Proceedings of the 5th International Protoplast Symposium, pp. 73-84. Edited by L. Ferenczy \& G. Farkas. Oxford: Pergamon Press. DAy, P. R. (1974). Genetics of Host Parasite Interaction. San Francisco: W. H. Freeman.

Demerec, M., Adelberg, E. A., Clark, A. J. \& Hartman, P. E. (1966). A proposal for a uniform nomenclature in bacterial genetics. Genetics 54, 61 76.

FERENCZY, L. (1981). Microbial protoplast fusion. Symposia of the Society for General Microbiology 31, $1-34$.

Gams, W. (1971). Cephalosporium-artige Schimmelpilze (Hyphomycetes). Stuttgart: Gustav Fischer.

HaLl, R. A. (1981). The fungus Verticillium lecanii as a microbial insecticide against aphids and scales. In Microbial Control of Pests and Plant Diseases, pp. 483-498. Edited by H. Burges. London: Academic Press.

HASTIE, A. C. (1964). The parasexual cycle in Verticillium albo-atrum. Genetical Research 5, 305-315.

Hastie, A. C. (1973). Hybridization of Verticillium albo-atrum and Verticillium dahliae. Transactions of the British Mycological Society 60, 511-523.

Hastie, A. C. (1978). Genetic analysis of species limits in Verticillium. In Taxonomy of Fungi, pp. 155-163. Edited by C. V. Subramanium. Madras, India: University of Madras.

Hastie, A. C. \& Heale, J. B. (1985). Genetics of Verticillium. In Phytophthologia Mediterranea, pp. 130-163. Italy: Unione Fitopatologica mediterranea.

HEALE, J. B. (1966). Heterokaryon synthesis and morphogenesis in Verticillium. Journal of General Microbiology 45, 419-424.

HeAle, J. B. (1982). Genetic studies on fungi attacking insects. In Proceedings of the 3rd International 
Colloquium on Invertebrate Pathology, Brighton, pp. 25-27.

Heale, J. B. (1987a). Genetics of Verticillium spp. Advances in Plant Pathology 6. London: Academic Press (in the Press).

Heale, J. B. (1987b). The potential impact of fungal genetics and molecular biology on biological control, with particular reference to entomopathogens. In Fungi in Biological Control Systems. Edited by M. N. Burger. Manchester: University Press (in the Press).

JACKSON, C. W. (1984). Genetical studies on the entomopathogenic fungus Verticillium lecanii (Zimm.) Viegas. PhD thesis, Queen Elizabeth College, University of London.

JACKSON, C. W. \& HeALE, J. B. (1985). Relationship between DNA content and spore volume in sixteen isolates of Verticillium lecanii and two new diploids of $V$. dahliae ( $=V$. dahliae var longisporum Stark). Journal of General Microbiology 131, 3229-3236.

Jackson, C. W., Heale, J. B. \& Hall, R. A. (1985). Traits associated with virulence to the aphid Macrosiphoniella sanborni in eighteen isolates of Verticillium lecanii. Annals of Applied Biology 106, 39 48.

MCGeary, F. M. \& Hastie, A. C. (1981). Hybridization of Verticillium albo-atrum strains from tomato and leucerne. In Abstracts of the 3rd International Verticillium Symposium, Bari, Italy, p. 42.

Messias, C. L. \& AZevedo, J. L. (1980). Parasexuality in the deuteromycete Metarhizium anisopliae. Transactions of the British Mycological Society 75, 473-477.

Peberdy, J. F. (1979). Fungal protoplasts: isolation, reversion and fusion. Annual Review of Microbiology 33, 21-39.

Pontecorvo, G. \& Sermonti, G. (1954). Parasexual recombination in Penicillium chrysogenum. Journal of General Microbiology 11, 94-104.

Puhalla, J. E. (1979). Classification of isolates of Verticillium dahliae based on heterokaryon incompatibility. Phytopathology 69, 1186-1189.

Puhalla, J. E. \& Hummel, M. (1981). Further studies on heterokaryon compatible populations within Verticillium dahliae. In Abstracts of the 3rd International Verticillium Symposium, Bari, Italy, p. 53.

Puhalla, J. E. \& Mayfield, J. E. (1974). The mechanism of heterokaryotic growth in Verticillium dahliae. Genetics 76, 411-422.

SiNGH, U. P. (1972). Anastomosis and nuclear condition in Cephalosporium coccorum Petch. Mycopathologia et mycologia applicata 48, 167-174.

TinLine, R. D. \& Noviello, C. (1971). Heterokaryosis in the entomogenous fungus Metarrhizium anisopliae. Mycologia 63, 701-721.

TYPAS, M. A. (1983). Heterokaryon incompatibility and interspecific hybridization between Verticillium albo-atrum and Verticillium dahliae following protoplast fusion and microinjection. Journal of General Microbiology 129, 3043-3056.

Typas, M. A. \& Heale, J. B. (1976). Heterokaryosis and the role of cytoplasmic inheritance in dark resting structure formation in Verticillium spp. Molecular and General Genetics 146, 17-26.

Wilson, J. F., Garnjobst, L. \& TATUM, E. L. (1961). Heterokaryon incompatibilities in Neurospora crassa, microinjection studies. American Journal of Botany 48, 299-305.

YurChenko, L. V., Zakharov, I. A. \& LeVitin, M. M. (1974). Genetics and selection of Beauveria bassiana (Bals.) Vuill., an entomopathogenic fungi. Genetika 10, $95-101$. 